\title{
Smart Home LPG Application Using GSM Network and Controlling Black- Marketing by RFID Technology
}

\author{
A Sasikala ${ }^{\mathrm{a},}{ }^{1}$, T Muthamizhan ${ }^{\mathrm{b}}$ \\ a Assistant Professor, Departmrnt of EEE, Sri Sairam Institute of Technology, West \\ Tambaram, Chennai-64. India \\ ${ }^{b}$ Associate Professor,Department of EEE, Sri Sairam Institute of Technology, West \\ Tambaram, Chennai-64. India
}

\begin{abstract}
The life style of an Indian family if evolving, particularly in the urban environment. Everyone in the family is perpetually busy, from the head of the family to possibly the youngest member of the family. As a result, essential works related to kitchen gas in the home gets neglected. Individuals for the most part know that gas can be death-defying. In any case, furthermost individuals still go out on a limb that can prompt damage. The greater part of these cases appears to be accustomed, so suggestions to utilize gas securely are continually required. This project aims at presenting a gas leakage detection kit to systematically detect the gas leakage and stop the gas leakage in sensitive locations by closing the gas cylinder valve automatically to ensure of further no leakage. Here specific gas sensor has been utilized which has high reactiveness for propane $(\mathrm{C} 3 \mathrm{H} 8)$ and butane $(\mathrm{C} 4 \mathrm{H} 10)$. Gas spillage system comprises of GSM (Global System for Mobile correspondences) module, which cautions the client by sending SMS. Additionally, an automated kitchen gas booking is also done in this project when the LPG goes empty. An innovative Radio Frequency Identification (RFID) based solution is used to avoid the usage of domestic cylinders in commercial sectors by automatic valve closing of cylinders and thus cutting off the gas supply.
\end{abstract}

Keywords. LPG Cylinder, Gas Sensor, RFID, LABVIEW, black-marketing.

\section{Introduction}

LPG, a combination of Commercial Propane and Butane soaked just like as unsaturated hydrocarbons. The gases being heavier than air may prompt suffocation when breathed in; likewise, the spilled gases when lighted may prompt blast. There is a requirement for a system to recognize and furthermore avert spillage of LPG. Nowadays, reserving an LPG cylinder is an instant message away and the Oil organizations have propelled the client well-disposed assistance called as IVRS (Interactive voice Response) system for their clients. Certainty, more often the people groups hand over old cylinder to the delivery person without knowing the precise amount of the gas left in it. In this research, LPG gauging machine is utilized to master this issue, and to screen and show the amount of gas in the cylinder. When gas level reaches beneath the edge furthest reaches of around $2 \mathrm{~kg}$ it sends SMS caution to the client just as gas refill organization, which utilizes a MQ5 gas sensor to identify

${ }^{1}$ A Sasikala, Assistant Professor, Department of EEE, Sri Sairam Institute of Technology, West Tambaram, Chennai-64.India. 
distinctive burnable gases with ease, and a PIC microcontroller to alarm when the degrees of gas recognized is past security point [7] of confinement. Furthermore, to take crisis measures to cut off the gas supply, when the spillage is distinguished. The alert utensil in the proposed system incorporates a LED sign, ringer and an alert SMS sent to the put away numbers with the support of GSM.The mishandling of household LPG cylinders is going unchecked in the present situation. The utilization of residential gas chambers rather than business ones is without a doubt the colossal value hole between the two chambers the cost of sponsored 14.2-kg cylinder for household purpose for existing is Rs.757 while that for 19-kg chamber implied for business use is Rs.1,350. This impacts the supply of the local gas cylinders to authentic customers and prompts deficiency. Also, a cylinder which is used by domestic consumers in the price range of Rs.600-700, is now available in black market for Rs.1200-1700.In this research work, steps have been taken to control black-marketing of LPG cylinders using RFID technology.

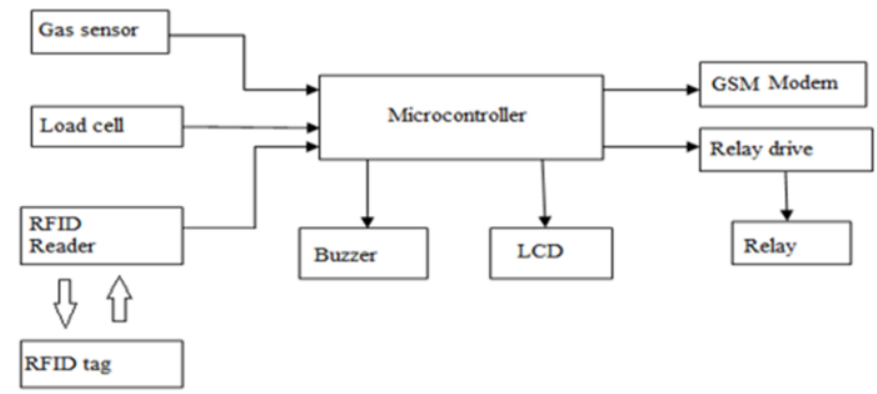

Figure 1. Functional blocks of RFID based safety home system.

The Microcontroller receives various field inputs from the different sources used. Gas sensors senses the leakage of LPG. The load cell measures the cylinder weight and the RFID Reader, RFID tag are used for tracking [1],[2]. GSM modem comprises of SIM card, used to send messages to concerned person when the leakage is detected. The relay system is used to control the exhaust fan and electronic valve. The core idea behind this work is to design an automatic system for LPG gas leakage detection [5],[6] and control has been done to prevent illegal usage of domestic cylinders in commercial sectors. This system is more reliable which ensures safety and prevents suffocation and explosion due to gas leakage.

\section{Necessity of smart gas cylinders}

The assembly of smart gas cylinder system detects the LPG spillage to maintain a strategic distance from fire mishaps giving house wellbeing highlight where security is a significant matter. The arrangement senses the spillage by employing a gas sensor, alarms the purchaser about the gas spillage by sending an SMS by utilizing the GSM and gives an alarm to the individuals about the gas spillage. At this point, when the system detects the LPG, focus noticeable all around surpasses the specific level then it promptly alert the shopper by sending SMS to indicated cell phone and cautions the individuals at home by enacting the caution which incorporates the LED, Buzzer all the while and show the message on LCD display. A safe Electronic valve is fitted to 
the LPG cylinder, which gives signal to cut off the gas supply to avoid further leakage.

\subsection{Consequence of LPG leakage}

LPG contains gas under pressure which is profoundly combustible. There could be two fundamental sorts of health threats related with the leakage: (i) happening because of breathing the gas, (ii) happening because of blast of the gas if there is a wellspring of start. Whenever breathed in, it can uproot air, deny the lungs of oxygen and cause hypoxia prompting suffocation. The gas can influence the mind and sensory system, trouble strolling or talking, absence of coordination, sickness and loss of awareness. Continual revelation may cause sorrow, seizures, cerebrum discharge and deactivated memory. Blast from LPG can bring about genuine consumes and can cause numerous wounds and even, demise. The usage of kitchen gas goes unnoticed and many times booking and buying of cylinders are done before it gets empty. This system provides convince to people by automatic booking of cylinders when gas in cylinders reaches empty level which isindicated by LCD display. Always on guard and at the ready, Gas detectors are the need of the hour providing security, safeguarding the home and thus saving lives from serious hazards caused by gas leakage.

\subsection{Black-marketing of LPG cylinders: A major issue}

The governing instructions issued under THE ESSENTIAL COMMODITIES ACT 1995provide for action; (1) to impound the stock seized, (2) to suspend/cancel licenses and (3) execute sentences like imprisonment for seven years. Illegal use of domestic cooking gas for commercial purposes is resulting in shortage of the cylinders in the town and adjoining rural areas. Shopkeepers pay extra money for refilling to the dealers and due to growing demand, inhabitants are craving for refilling. This blackmarketing of cylinders resulted in huge loss to government economy. Consumption of gas cylinders per year per family is a set by the central Government to 12, people are facing hardships, particularly in rural areas.

\subsection{Role of smart cylinders in controlling black-marketing}

A RFID reader interfaced with PIC microcontroller of gas leakage detection kit contains separate coding for domestic and commercial cylinders. The reader is separately programmed for domestic and commercial cylinders. When the cylinder is placed on the load cell of the kit the following operations are performed: (i) If the tag code and program of reader matches (i.e domestic coding for domestic program of reader) then the supply of gas is continued without interruption. (ii) If the tag code and program of reader mismatches (i.e domestic coding for commercial program of reader) then the gas supply is cutoff by automatic closing of electronic valve. In existing system, automatic control action to prevent the leakage of LPG is provided by closing of gas regulator knob using mechanical handle operated by stepper motor. This system cannot control the selling of domestic cylinders in black-market by customers. 


\section{Hardware Implementation Of Smart Home Application}

In this work, Peripheral Interface Controller are used to monitor the LPG gas leakage in the house with RFID reader to control Black-marketing. The block diagram of the proposed system is shown in the figure 2. The block diagram shows the working of the PIC microcontroller-built with (PIC18F45K22) LPG Automation system with RFID based Black-marketing control system. The LPG gas cylinder is given as the input to the Load cell, which converts mechanical force into electrical signal, has an internal strain gauge coupled with Wheatstone bridge. The gas sensor, sense and control the gas level present in the kitchen and sensor output is converted into digital signals by the ADC with PIC microcontroller unit. Once the gas gets sensed, the microcontroller [3],[4] sends the signal to relay switch to turn ON the exhaust fan and the electronic valve to close automatically. The alarm system and the GSM system is used to send an alert message to the concerned, when they are in outstation. The cylinder weight is displayed in LCD display as full/medium/empty for easy visualization. Once the cylinder gets empty, the system automatically books the gas cylinder by sending message to gas agencies. The RFID reader finds that the given information is false, the relay gets turn $\mathrm{ON}$ the electronic valve to cut off the gas supply. The electronic apparatus, function when the supply is a $+5 \mathrm{~V}$ or $+12 \mathrm{VDC}$. It is stepped down to 5V DC by LM7805 Regulator. LED's are provided to indicate the working condition of regulators and the resistors are used to regulate the current flow. In-Circuit Serial Programmer (ICSP) is given to MCLR/VPP/RE3 of the PIC to transfer program from Personal Computer (PC) to Microcontroller unit using ICSP pins. Inputs such as the MQ-5 gas sensor, Load cell, Instrumentation Amplifier AD620 and RFID reader LFDT125R are given to the PIC18F45K22 microcontroller's input side as shown in the circuit diagram. The communication device Universal Asynchronous Receiver / Transmitter (UART) of the port RC6 and RC7 of the PIC is connected to GSMmodem.

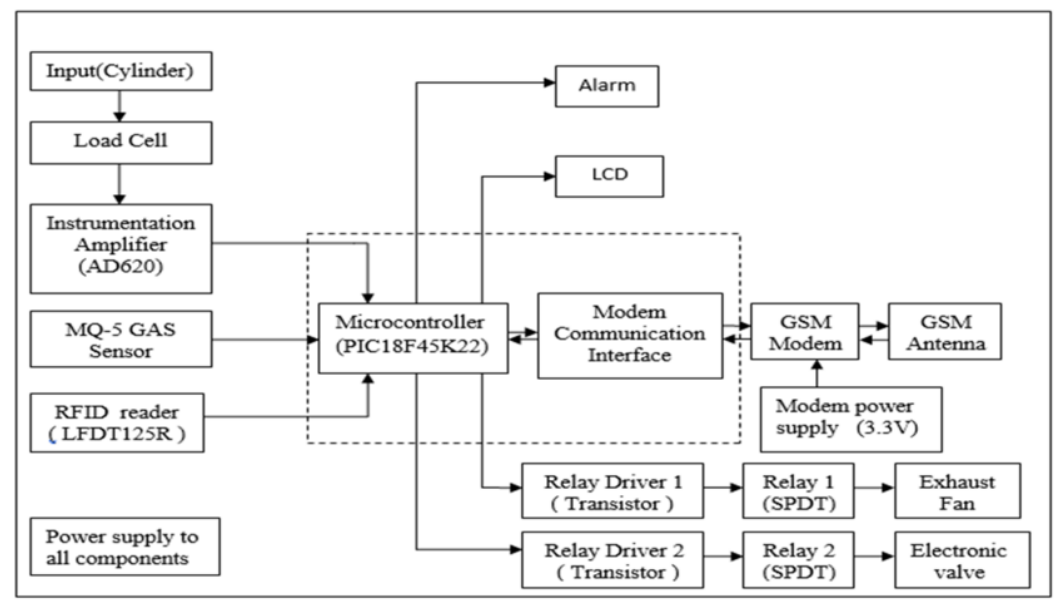

Figure 2. Detailed Block Diagram of Smart Home Application 


\subsection{Hardware Components}

The components used are PIC18F45K22, Load cell, Instrumentation amplifier, Gas sensor, LCD, GSM Modem, Relay, Solenoid valve, RFID tag and RFID reader. The PIC18F45K22 is a 40-pin low power, high performance 8-bit microcontroller with XLP Technology. PIC18F45K22 device can be serially programmed by microcontroller using PIC KIT-3 USB converter with Personal Computer (PC) and ICSP with the help of In-Circuit Serial Programmer using ICSP pins, with two lines for programmable clock and programmable data and three other lines for power supply, ground and the programming voltage. The AD620 is a low cost, high precision instrumentation amplifier and MQ-5 gas sensor [9-11] is highly sensitive to Methane, Propane and Butane; Sensitive substance of $\mathrm{MQ}-5$ is $\mathrm{SnO}$, which lower the conductivity in clean air and higher the conductivity when gas concentration increases. The SPI bus (Serial Peripheral Interface) is a synchronous serial data link between LCD and microcontroller. The GSM Modem has a similar function to a conventional mobile phone. The heart of the GSM modem is a GSM module,that handles the functions of making calls, sending receiving SMS etc. Any wireless communication device [8] the GSM modem also has an antenna for transmitting and receiving RF signals to and from the GSM network. In this prototype UARTs is used for transmitting and receiving data. AT commands are digital commands to perform any function on a GSM modem.

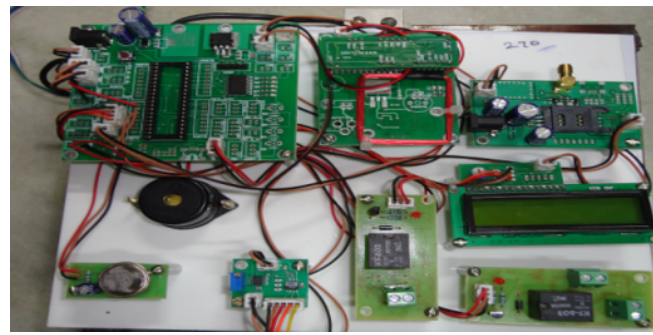

Figure 3. Snapshot of the Hardware Implementation

\subsection{RFID Technology}

Radio frequency identification (RFID) technology employs radio waves to identify people, objects and the system comprises of (1) RFID tag or transponder and (2) RFID reader or transceiver. The RFID tag is framed by an antenna, a wireless transducer and an encapsulating material. These tags can be three types (1) Active tags , (2) Passive tags and (3) Semi-passive tags. An RFID reader (e.g. LFDT125R) consists of antenna, transceiver and decoder, sends periodic signals to inquire about any RFID tag in its neighborhood. The RFID reader continuously emits radio waves up to certain range and the tag receives energy form the radio waves and get activated. The reader then gives command to the tag and respond to the reader by passing the information to the Microcontroller. The Microcontroller sends the signal as voltage to relay to get turn on and control the devices. 


\section{Simulation Results and Analysis}

LABVIEW are used as front end and interface SCADA software with the PLC (user interface) purpose and monitoring the gas leakage process. In this section the simulation results using the SCADA tool are explained. The computer and LABVIEW are linked to server through PLC. The Figure 4 shows the back panel of Virtual Instrumentation and the block diagram, comprises of graphical source code. All of the items placed on the back panel will look on the front panel as terminals i.e Simulation panel.

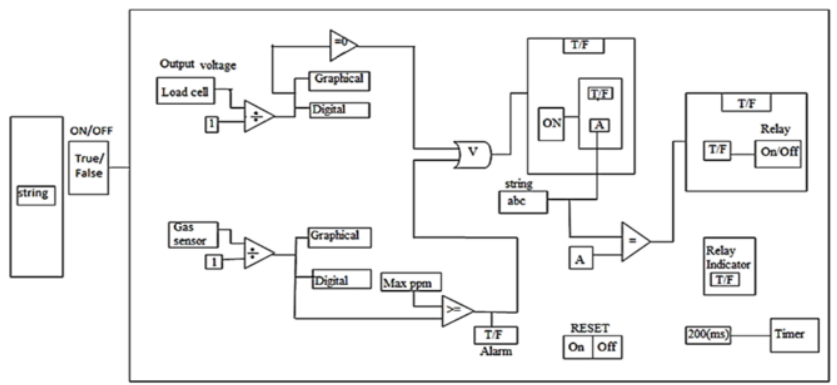

Figure 4. Simulation Block Diagram

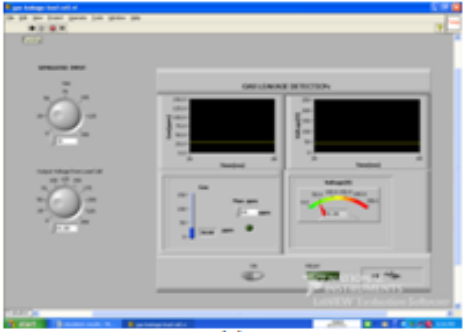

(a)

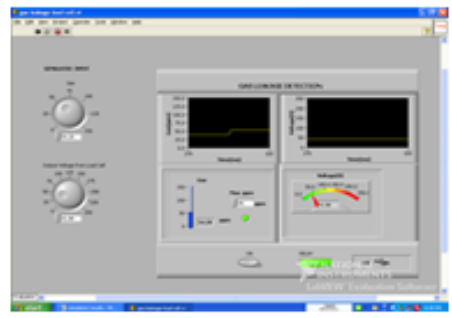

(c)

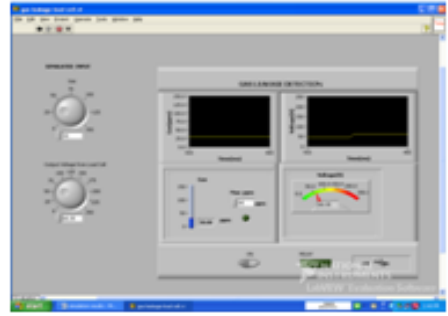

(b)

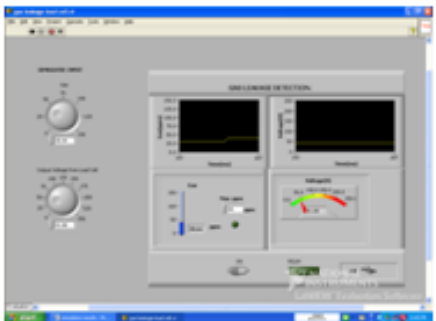

(d)

Figure 5. Simulation Panel - the HMI of PLC- SCADA interface.

The screen shows gas level and voltage level indicator. Based on the readings sensed by the sensor placed in the respective places and the values set by the users, the PIC microcontroller controls the output through the relays. The simulation panel indicates the turn $\mathrm{ON}$ of the control switch for the entire circuit from the off condition. Figure 5 (a) shows the running mode after the circuit switch get turned on. The LPG gas sensor is simulated and the gas level is $30 \mathrm{ppm}$ indicated in the scale. Figure 5 (b) and (c) 
shows the level of gas as $39.44 \mathrm{ppm}$ which is less than preset value. Hence the alarm and relay are in OFF condition. In the figure 5 (d), shows the gas level has reached $54.28 \mathrm{ppm}$ which is more than the present value. Hence the alarm and relay get turned on which is indicated by the green light. The above image shows the output voltage from the load cell by the given input $60.35 \mathrm{~V}$ and it is indicated in the scale.

\section{Conclusion}

The control of home in real-time at low cost, by the use of sensors and relays makes the system simpler and easily controllable. The system helps the customers to book the cylinder automatically and reduces the effort of knowing the weight of the cylinder. The problems associated with the use of LPG gas can be prevented and the loss of lives and property can be reduced. The RFID identifying and GSM messaging systems can enhance automatic management, data security and anti-theft digital logistics management. The Merits of this project are (1) Gas leakage detection and the valve can be closed automatically, (2) Automatic Kitchen Gas booking (3) An automatic system, (4) Improves Government economic level by controlling blackmarketing. (5) Accumulation of combustible gases prevention. It finds application in Home, Hospital for patient monitoring, Industries for machinery monitoring, and chemical industries. In future, improvements can be done in the system with GPS technology for tracking the vehicles. To power the system, rechargeable batteries can be used to can send the address of home as message to fire brigade.

\section{References}

[1] M. S. Alam, M. W. Alam and T. Sultana, RFID based Room Automation, Proceedings of the International Conference on Mechanical Engineering and Renewable Energy 2013 (ICMERE2013) 1-3 May 2014.

[2] K.Shingala, J, Patel, Automatic Home Appliances and Security of Smart Home with RFID, SMS, Email and Real Time Algorithm Based on IOT, International Research Journal of Engineering and Technology (IRJET), Vol. 04, no. 04, Apr -2017

[3] A. I. Adekitan and V. O. Matthews and Olayinka Olasunkanmi, A microcontroller based gas leakage detection and evacuation system", IOP Conference Series: Materials Science and Engineering, 413 (2018) 012008.

[4] B. Sonkar B, A. Sood, A. Ranjan and A. Faisal, Microcontroller Based LPG Leakage Detector Using GSM Module International Journal of Electrical and Electronics Research (2015), pp. 264-269

[5] V. Carmela and I. Ana, Smart gas detection system, Institute of Electrical and Electronics Engineering(2017).

[6] S. Rajitha and T. Swapna, "Security alert system using GSM for gas leakage”, International Journal of VLSI and Embedded Systems, Vol.3, No.4, (2012), pp. 173-175

[7] D. Chandrababu, V. Meenakshi and E. Mohan, Security System with Three Way Authentication, Advances in Robotics \& Automation (2017), Vol 6(3): 176

[8] I. Mohammed and E.Duman, Implementation of a Smart House Application using Wireless Sensor Networks, Computer Science \& Information Technology (CS \& IT) (2017), 53-70,

[9] V.D.Ambeth Kumar (2018), “ NOVEL WIRELESS SENSING SYSTEM FOR THE WELFARE OF SEWER LABORERS”, Healthcare Technology Letters (IET) Volume 5, Issue 4, p. 107 -112

[10] V.D.Ambeth Kumar, (2016) "Human Life Protection In Trenches Using Gas Detection System" for the Journal of Biomedical Research. Vol.27 (2): 475-484, 2016.

[11] V.D.Ambeth Kumar, (2016) "Human security from death defying gases using an intelligent sensor system" for the Sensing and Bio-Sensing Research - Journal - Elsevier, Vol.7, pp.107-114. 